\title{
Factors associated with signs of temporomandibular pain: an 11- year-follow-up study on Finnish adults
}

\section{TEMPOROMANDIBULAR PAIN SIGNS IN ADULTS}

\author{
Aisha Banafa ${ }^{1}$, Anna Liisa Suominen ${ }^{2,3,4}$, Kirsi Sipilä ${ }^{2,5,6}$ \\ ${ }^{1}$ Doctoral student, Early Stage Researcher, Faculty of Health Sciences, School of Medicine, Institute of \\ Dentistry, University of Eastern Finland, Kuopio, Finland. \\ 2 Institute of Dentistry, University of Eastern Finland, Kuopio, Finland \\ 3 Department of Oral and Maxillofacial Diseases, Kuopio University Hospital, Kuopio, Finland \\ 4 Public Health Evaluation and Projection Unit, National Institute for Health and Welfare (THL), Helsinki, \\ Finland \\ ${ }^{5}$ Research Unit of Oral Health Sciences, Faculty of Medicine, University of Oulu, Oulu, Finland \\ ${ }^{6}$ Oral and Maxillofacial Department, Medical Research Center Oulu, Oulu University Hospital, Oulu, Finland
}

\section{Acknowledgements}

This study is based on the Health 2000 and the Health 2011 Surveys, which were organized by the National

Institute for Health and Welfare of Finland (THL) (https://thl.fi/fi/tutkimus-jaasiantuntijatyo/vaestotutkimukset/terveys-2000-2011), the former National Public Health Institute (KTL), and was partly supported by the Finnish Dental Society Apollonia and the Finnish Dental Association. We would like to acknowledge Mrs. Riitta Myllykangas for her assistance in statistical analysis. A personal grant from the Finnish National Agency for Education (CIMO) to Aisha Banafa is acknowledged with gratitude.

\section{Disclosure statement}

The authors declare no potential conflict of interests with regard to the submitted article. 


\begin{abstract}
Background: (Pain in the temporomandibular region is a main complaint causing disability and distress among TMD sufferers.)

Objectives: The aim of the study was, over an 11-year follow-up on Finnish adult population, to investigate the prevalence of clinically assessed pain-related TMD signs, i.e., TMJ and MM pain on palpation, and their association with sociodemographic background and denture status.

Methods: The data were based on the nationally representative Finnish Health 2000 and Health 2011 Surveys (BRIF8901). The sample comprised 1,210 adults who underwent clinical oral examinations including TMD signs assessment. Statistical evaluations included chi square tests and logistic regressions. Results: The prevalence of palpatory MM pain deceased from $9.5 \%$ at baseline to $4.6 \%$ in the follow-up. Cross-sectionally, presence of palpatory MM pain significantly associated with gender $(p<0.001, p=0.002)$ and educational level $(p<0.001, p=0.001)$ in both years, and with age $(p=0.006)$ and denture status $(p=0.022)$ at baseline. The prevalence of palpatory TMJ pain increased from $2.1 \%$ at baseline to $3.5 \%$ in the follow-up. Presence of palpatory TMJ pain significantly associated with gender in both years ( $p=0.012$, $\mathrm{p}=0.032$ ). Female gender, lower education and palpatory MM pain at baseline predicted palpatory MM pain in the follow-up.
\end{abstract}

Conclusion: Palpatory MM pain is relatively prevalent in adults, yet with a favorable prognosis. Women and people with low education are more susceptible groups. Previous experience of palpatory MM pain increase the risk of exhibiting it later in life.

Keywords: Temporomandibular disorders, masticatory muscle pain, temporomandibular joint pain, longitudinal-follow-up study, adult population. 


\section{Introduction}

Temporomandibular disorders (TMD) is a collective term denoting dysfunction and pain related to the masticatory muscles (MM), temporomandibular joints (TMJ), and associated structures ${ }^{1}$. Signs and symptoms include TMJ noises, deviation in the mandible movement, and MM and/or TMJ pain². TMD are multifactorial in origin. Several factors, including psychological factors, occlusal factors, traumas, factors related to joint pathology, deep pain input, and parafunction ${ }^{1,3}$, can either cause TMD, increase the risk of TMD, impair healing, or enhance the progression of pre-existing TMD ${ }^{4}$.

TMD are prevalent in population; based on the Health 2000 Survey of Finnish adults, $38 \%$ of the participants had at least 1 sign of TMD, i.e., maximum inter-incisal distance $<40 \mathrm{~mm}$, crepitation, TMJ clicking, TMJ pain, or MM pain, based on clinical oral examination ${ }^{5}$. Moreover, almost $6 \%$ of that study population showed clinically determined TMD findings associated with back pain, shoulder and neck pain as well as joint pain ${ }^{6}$, and there was an association found between TMD and edentulousness, wearing complete denture, and the condition of denture in women ${ }^{7}$. Likewise, a Northern Finland 1966 Birth Cohort Study reported that the prevalence of TMD signs was $34.2 \%$ among clinically examined subjects, with TMJ clicking and MM pain on palpation being the most common signs ${ }^{8}$. Furthermore, self-reported TMD pain also appears to be frequent among Finnish university students ( $25.9 \%$ of women, $11.4 \%$ of men $)^{9}$. An earlier investigation of Finnish adolescents observed that $48 \%$ of the study participants had reported TMJ clicking at least once throughout 9 years, and that the prevalence increased with age ${ }^{10}$. TMD signs and symptoms can fluctuate through time, resolve, or become chronic. Fluctuation of TMD has been noticed in different longitudinal studies. In Japan, a longitudinal study performed on high school students reported fluctuation of TMD signs over the 3 -year-period of the study ${ }^{11}$. Similarly, an epidemiological study by Magnusson et al. ${ }^{12}$ observed a substantial fluctuation in TMD signs among participants over 20 years. Another Swedish 10-year-follow-up study also observed fluctuation of TMD symptoms in participants during the period of age 17 to 28 years, but with a significant difference in the 
disease course between genders; $92 \%$ of the women versus $29 \%$ of the men who reported symptoms of TMD at the age of 17 years also reported these symptoms 10 years later ${ }^{13}$. Some studies hypothesized that the fluctuation of TMD signs may be related to the fluctuation of possible background factors such as insomnia and hormones ${ }^{14,15}$.

As for chronicity of TMD, the presence of TMD symptoms in early childhood could be a predictor of chronic TMD in adulthood ${ }^{16}$. The same applies to adults; a 10-year follow-up study conducted on 50 -year-old cohort participants found that reporting TMD symptoms at baseline increased the odds of reporting them 10 years later ${ }^{17}$. Furthermore, muscle disorder and the presence of frequent pain have been suggested as predictors for developing chronic $\mathrm{TMD}^{18}$, as well as the number of painful palpation sites and overall body sites in pain ${ }^{19}$. Moreover, high stress levels were found to increase the risk for chronic facial pain, yet it was suggested that association was mediated by depression ${ }^{20}$.

The background behind pain-related TMD signs is yet not fully understood, and it appears to be an interaction between different general factors governed by individual-specific factors. Few studies have addressed those factors and their long-term effect; however, using relatively small sample sizes or samples not representative of population. Therefore, further longitudinal studies with large representative samples are needed.

Arising from the importance of a biopsychosocial approach in studying pain, this study aimed to investigate the longitudinal change in the prevalence of two clinically assessed pain-related TMD signs, i.e., TMJ pain and MM pain on palpation, based on an 11-year follow-up on Finnish adults, and to study their association with gender, age, number of teeth, denture status, and educational level. The hypothesis here is that the risk for exhibiting TMJ pain and/or MM pain on palpation increase in relation with genderrelated factors, aging, the accompanying loss of teeth and the use of dentures as well as low socioeconomic status represented by educational level..

\section{Material and Methods}


The data for the study were based on the comprehensive, nationally representative Finnish Health 2000 and Health 2011 Surveys, carried out by the National Institute for Health and Welfare (THL) ${ }^{21,22}$. The main sampling frame in 2000 comprised 8,028 adults aged 30 years or over, living in mainland Finland, of whom 6,986 (87\%) were interviewed in their home or in an institution, and $79 \%$ participated in health examinations including oral health ${ }^{23}$. The two-stage stratified cluster sample was representative of the whole Finnish population aged 30 years or over, allowing for good generalizability of the results. Persons aged 80 years and over were oversampled by doubling the sampling fraction ${ }^{21}$.

Sociodemographic background information including gender, age and education were obtained during home interviews ${ }^{21}$. Information on number of teeth and removable dentures were obtained through clinical oral examination ${ }^{23}$. All teeth were counted to obtain number of teeth, including third molars, deciduous teeth and tooth remnants that were visible or tactile in the mouth during the examination. If both deciduous and the respective permanent tooth were present, the latter one was counted. Removable denture type (i.e. partial or complete) was recorded separately for the upper and the lower jaw.

\section{Assessment of TMD signs}

A standardized clinical oral examination was performed by five calibrated and experienced dentists, who assessed the signs of $\mathrm{TMD}^{23}$. The examiners were trained prior to the examinations by experienced specialists in order to increase the reproducibility of the clinical examination. The assessment of TMD signs included recording of maximum mouth opening, auscultation of TMJ noises, and palpation of the TMJs and two MM, i.e., temporalis anterior and masseter superficialis. TMJ tenderness to palpation was assessed by applying a force of about $0.5 \mathrm{~kg}$ over the immovable condyle, and MM tenderness was assessed with a force of about $1 \mathrm{~kg}$. Attempts were made to standardize the palpation force by exerting the forces on a measuring scale (using a letter weighing scale) between the examinations. TMJ and MM pain on palpation was recorded if the subjects reported pain when asked or showed a protective reflex. 
Except for the maximum inter-incisal distance, all the findings were recorded separately for both sides. The percentage agreement between examiners and the referent examiner was: 92\% (Kappa value, 0.26; $95 \% \mathrm{Cl}, 0.19-0.34$ ) for pain in joints and $95 \%$ (Kappa value, $0.47 ; 95 \% \mathrm{Cl}, 0.41-0.53$ ) for pain in masticatory muscles.

All participants included in the Health 2000 Survey were invited to participate in the Health 2011 Survey $^{22}$. The sample of those aged 30 or over comprised 7,964 participants. Clinical oral examinations were carried out in the same manner as in the Health 2000 Survey; however, due to limited resources they only covered subjects who were living in Southern (Hospital Districts of Helsinki and Uusimaa) and Northern (Hospital Districts of Kainuu, Keski-Pohjanmaa, Pohjois-Pohjanmaa, Lappi, Länsi-Pohja, Pohjois-Savo, and Vaasa) Finland, with $41 \%$ participation rate ${ }^{24}$.

For this study, those who participated in the clinical oral examination and TMD signs assessment in both surveys (the Health 2000 and the Health 2011) were included. The final study sample comprised 1,210 participants (535 men, 675 women).

When encoding the variables, the subject was considered TMJ-pain positive in the presence of pain on palpation on either side of TMJs, and negative in the absence of pain on both sides. The corresponding criteria were set for $\mathrm{MM}$ pain, i.e., those having pain in either of the MM were set as MM-pain positive. Age was encoded into five age groups: 40 years or under, $41-50$ years, 51-60 years, 61-70 years, and 71 or older. The number of teeth variable was encoded as follows: 0 teeth, 1-19 teeth and 20 or more teeth, based on the notion that 20 teeth are the limit for adequate function, below which a reduction in the masticatory efficiency can occur ${ }^{25}$. Denture status variable was based on number of teeth and the presence of removable denture and was encoded as follows: dentate with no denture, dentate with denture, and edentulous or with complete denture. Educational level was trichotomized into basic, intermediate and higher education. The basic education category included those with no formal vocational training or senior secondary education, intermediate education included those who had 
completed vocational training or passed the matriculation examination, and higher education included those with degrees or diplomas from higher vocational institutions, polytechnics, and universities.

\section{Statistical analysis}

The statistical significance of TMJ/MM pain on palpation association with age group, gender, number of teeth, denture status, and educational level were evaluated using chi squared tests both at baseline and in the follow-up. Logistic regression analyses were used to analyze the associations between the explanatory variables at baseline (presence of TMJ/MM pain on palpation, gender, age as a continuous variable, number of teeth, denture status, and educational level) and the presence of TMJ/MM pain on palpation in the follow-up. To obtain representative results for the target population, both the surveys used stratified cluster sampling and took into account the non-response rate by using weight coefficients. The data analyses were performed using SAS Callable SUDAAN software (Release 11.0) to take into account the two-stage cluster sampling design.

\section{Results}

At baseline, the prevalence of MM pain on palpation was $9.5 \%$ ( $4.7 \%$ of men / 13.6 of women, $p<0.001)$ and was the highest among the 61-70-year-olds, complete denture wearers, and those with basic education (Table 1). The prevalence of TMJ pain on palpation was $2.1 \%(0.6 \%$ of men $/ 3.3 \%$ of women, $\mathrm{p}=0.012$ ) and was the highest among the 71-year or older, complete denture wearers and basic education group; however, with no significant associations (Table 1). In the follow-up, the prevalence of MM pain on palpation was $4.6 \%$ ( $2.4 \%$ of men / $6.5 \%$ of women, $p=0.002)$, and associated significantly with level of education being the highest among those with basic education (Table 1). The prevalence of TMJ pain on palpation was $3.5 \%$ ( $2.4 \%$ of men / $4.4 \%$ of women, $p=0.032$ ), with no significant associations with the other factors (Table 1).

In the logistic regression analysis, none of the explanatory variables at baseline were associated with the presence of TMJ pain on palpation in the follow-up, though the estimate $(\mathrm{OR}=2.0,95 \% \mathrm{Cl} 1.0-3.8)$ for 
female gender was elevated and almost significant $(p=0.060)$ (Table 2). The presence of MM pain on palpation at baseline ( $\mathrm{OR}=8.2,95 \% \mathrm{Cl} 4.7-14.4)$, basic education ( $\mathrm{OR}=3.7,95 \% \mathrm{Cl}$ 1.9-7.3), intermediate education ( $\mathrm{OR}=2.4,95 \% \mathrm{Cl}$ 1.1-5.0) and female gender ( $\mathrm{OR}=2.1,95 \% \mathrm{Cl}$ 1.0-4.3) were strong predictors for the presence of MM pain on palpation in the follow-up, whereas all other factors showed insignificance (Table 2).

\section{Discussion}

The present study showed that the prevalence of clinically assessed pain-related TMD signs varied during the 11-year follow-up period. The prevalence of MM pain on palpation decreased from $10 \%$ to $5 \%$, whereas TMJ pain on palpation increased from $2 \%$ to $4 \%$. Presence of MM pain on palpation at baseline, low education, and female gender increased the risk of the presence of MM pain on palpation in the follow-up.

Women showed a higher prevalence of TMJ and MM pain on palpation compared to men, thus confirming the results from previous studies $5,8,9,26,27$. The higher prevalence among women could be partly related to their higher tendency to report pain compared to men $^{28}$. Furthermore, in the present study female gender significantly increased the odds of exhibiting MM pain on palpation in the follow-up, and the same was observed for TMJ pain on palpation, although the association was not significant. The higher prevalence among women might also be related to the effect of female hormones on lowering the pain threshold ${ }^{15}$. Moreover, pain upregulation mechanisms could also give a plausible explanation; studies have proposed that patients with pain-related TMD suffer from a generalized hyperexcitability in their central nociceptive pathways ${ }^{29,30}$, which women are at a higher risk of due to the greater temporal summation and after sensation they exhibit compared to men $^{31}$. The prevalence of MM pain on palpation decreased markedly in women during the follow-up, which could possibly be partly related to increase in the age of the cohort and related hormonal changes ${ }^{32}$. 
At baseline, the prevalence of $\mathrm{MM}$ pain on palpation decreased from the youngest age group and increased substantially in the 61-70-year age group, and then decreased towards the oldest-age group. In the follow-up the prevalence decreased in the 41-50-year age group (previously $\leq 40$ ) and peaked at the age of $\geq 71$ years (previously $61-70$ ). The prevalence of MM pain on palpation was significantly associated with age only at baseline. On the other hand, the prevalence of TMJ pain on palpation was independent of age in both years. Longitudinally, age at baseline did not associate with exhibiting pain on palpation (i.e., MM pain and/or TMJ pain) in the follow-up. The association between TMD and age varies between studies; some studies have reported a negative association between TMD symptoms and increasing age $\mathrm{a}^{33,34,35}$, while others have found them to be independent ${ }^{36}$. On the other hand, some studies have shown a positive association between clinical TMD signs and increasing age ${ }^{35,37}$, thus at least partly support the present results. Some studies have suggested that, compared to the younger groups, the older individuals accept more physiological dysfunctions and report less symptoms, whereas they have more clinical signs ${ }^{35}$. Other studies have found that both signs and symptoms of TMD increase with age and attribute it partly to the use of dentures ${ }^{26}$. So far it appears that different study designs affect the reported prevalence in different age groups. The present findings suggest that age itself is not a major contributive factor to clinically assessed pain-related TMD signs, but rather the other backgrounds that prevail in certain age groups in a given society.

The current results showed a high prevalence of MM pain on palpation among complete denture wearers with a significant association only at baseline, which implies a weak contribution to the pain; however, it should not be overlooked. While some clinical cross-sectional studies have found a significant association between TMD and the use of partial denture ${ }^{38,39}$, clinical follow-up studies and literature reviews have found no direct association between TMD and teeth loss or denture use $e^{40,41,42}$ which could support the current results. Previous investigation on the Health 2000 participants has found an association between clinically assessed TMD signs, edentulousness, and denture use in women ${ }^{7}$. In the present study, although 
local factors such as number of teeth and denture status had a more remarkable role at baseline on the prevalence of MM pain on palpation; after follow-up of the cohort for 11-years they did not associate with the presence of such pain and the prevalence decreased markedly among complete denture wearers, which suggests the involvement of other confounders in the background within the timeline. It should be taken into consideration that the treatment of edentulousness has improved in Finland in the past decade, including treatment approaches such as implant-supported overdentures, which could at least partly explain the observed differences. However, further investigations are needed to clarify this. Another explanations could be related to the increased awareness of health upkeep among individuals, the fluctuating nature of such pain, or body adaptability ${ }^{1}$.

In the present study, the presence of MM pain on palpation associated significantly with the educational level at baseline and in the follow-up, with increasing prevalence with lower education. Furthermore, having a lower education at baseline significantly increased the risk of exhibiting MM pain on palpation in the follow-up. The possible effect of education could be mediated through low income, which leads to a poor response to increasing living demands, which in turn increases the risk of psychosocial-related health issues. The troublesome area of low income has been linked to depressive and anxiety disorder ${ }^{43}$; moreover, earlier investigations on the baseline sample have found an association between clinically assessed TMD signs and psychological distress ${ }^{44}$, which might be a possible explanation for the current results; however, this remains to be determined. On the other hand, a low educational level did not associate with the presence of TMJ pain on palpation in the follow-up, suggesting that socioeconomic status might not have a major influence on TMJ pain.

Generally, MM pain on palpation was more prevalent than TMJ pain on palpation in both years, the same was found in another Finnish birth-cohort study ${ }^{8}$ and also by Magnusson et al. ${ }^{12}$.Addtionally, in a study on TMD first-onset more subjects developed MM pain compared to TMJ pain, ${ }^{37}$. which supports the current findings and point out the different pathophysiology of the two pain signs. Furthermore, during the 11- 
year follow-up the prevalence of MM pain on palpation decreased suggesting a favorable prognosis, which was consistent with several long-term longitudinal studies ${ }^{10,12,17}$. On the other hand the prevalence of TMJ pain on palpation increased among the cohort within 11 years suggesting that it might be a condition that develops in adults over time; yet, the associated backgrounds could not be determined in this study. Similarly, Johansson et al. reported an increase in TMJ pain over 10 years among adults ${ }^{17}$. Despite that, pre-existing MM pain on palpation showed an eightfold risk of appearance in the follow-up compared to twofold risk for TMJ pain on palpation that was not statistically significant. This could suggest that individuals showing $\mathrm{MM}$ pain on palpation at a given time are more susceptible to recurrence, and this could be mediated (among other factors) by gender and educational level. Such factors (i.e., female gender and poor socioeconomic status) have been linked to chronic pain conditions according to different studies $^{31,45}$, which may in part explain the current results.

Several studies have shown that TMD signs and symptoms typically fluctuate ${ }^{10,11,12,13}$. The present study also showed that clinically assessed pain-related TMD signs are not constant in a relatively long-time interval, whereas it was not possible to investigate the fluctuation during shorter time periods due to lack of information between the time points. Some longitudinal studies have observed the presence of fluctuation in TMD symptoms or signs either in short- or long-time intervals. A 20-year longitudinal study on adolescents observed a substantial fluctuation in signs and symptoms of TMD at 5, 10, and 20 years from the first examination ${ }^{12}$. Könonen et al. ${ }^{10}$ also observed the fluctuation of TMJ clicking in adolescents over 9 years. Moreover, some studies have attempted to explain the fluctuation of TMD and linked it to the fluctuation of background factors that affect the pain threshold, such as the hormonal changes during the menstrual cycle ${ }^{15,32}$, and severity of insomnia ${ }^{14}$, for instance.

\section{Limitations and strength of the study}

Due to the study design, the results can be generalized to adults living in northern and southern Finland; however, the data represent two large areas with various living conditions. The follow-up time interval 
was relatively long, which is also a strength of the study. Furthermore, the study reported objective painrelated TMD signs based on clinical assessment performed by trained professionals, which is more reliable than relying on subjective symptoms alone. One of the limitations was that the participation rate in the clinical oral examination was lower in the follow-up ( $41 \%$ compared to $79 \%$ at baseline). The present study compared prevalence of clinically assessed pain-related TMD signs between the data collections in 2000 to 2011 , and no information on the occurrence of the signs and their fluctuation between these time points was available. Moreover, pain-related TMD signs were determined based only on palpation of MM and TMJ, which did not allow a conclusive diagnosis of TMD to be made. Using validated, international diagnostic protocols, such as RDC/TMD, or recently developed Diagnostic Criteria for Temporomandibular Disorders (DC/TMD) was not possible for practical reasons related to the large sample size.

\section{Conclusions}

Based on the results of the present study it could be concluded that palpatory MM pain is prevalent in adults compared to TMJ pain; however, with a favorable prognosis in the long term. Women and people with a low level of education seem to be more susceptible to exhibiting such pain. Those who have experienced palpatory MM pain before have a higher risk to experience it later in life. Neither age nor denture status seem to perpetuate palpatory pain in either MM or TMJ. Palpatory TMJ pain appears to be a progressive condition in adults, indicated by the overall increase in its prevalence in the 11-year followup. Additionally, the differences between palpatory TMJ and MM pain with regard to prevalence and association with background factors emphasize the different pathophysiology. Finally, it seems that sociodemographic factors do not pose much risk on adults for developing TMJ pain.

\section{References}

1. Okeson JP. Management of Temporomandibular Disorders and Occlusion. St. Louis, MO: Elsevier/Mosby; 2013. p. 102-161.

2. Dworkin SF, LeResche L. Research diagnostic criteria for temporomandibular disorders: review, criteria, examinations and specifications, critique. J Craniomandib Disord 1992;6:301-355. 
3. Malik NA. Textbook of Oral and Maxillofacial Surgery. New Delhi: Jaypee Brothers Medical Publishers (P) Ltd.; 2012. p. 239-277.

4. De Leeuw, ed. Orofacial pain. Guidelines for assessment, diagnosis, and management. 4th ed., Chigaco: Quintessence; 2008. p. 129-175.

5. Rutkiewicz T, Könönen M, Suominen-Taipale L, Nordblad A, Alanen P. Occurrence of clinical signs of temporomandibular disorders in adult Finns. J Orofac Pain 2006;20:208-217.

6. Sipilä K, Suominen AL, Alanen P, Heliövaara M, Tiittanen P, Könönen M. Association of clinical findings of temporomandibular disorders (TMD) with self-reported musculoskeletal pains. Eur J Pain 2011;15:1061-1067.

7. Sipilä K, Näpänkangas $R$, Könönen $M$, Alanen $P$, Suominen AL. The role of dental loss and denture status on clinical signs of temporomandibular disorders. J Oral Rehabil 2013;40:15-23.

8. Jussila P, Kiviahde H, Näpänkangas R, Päkkilä J, Pesonen P, Sipilä K, Pirttiniemi P, Raustia A. Prevalence of Temporomandibular disorder in the northern Finland birth cohort 1966. J Oral Facial Pain Headache 2017;31:159-164.

9. Huhtela OS, Näpänkangas R, Joensuu T, Raustia A, Kunttu K, Sipilä K. Self-Reported Bruxism and Symptoms of Temporomandibular Disorders in Finnish University Students. J Oral Facial Pain Headache 2016;30:311-317.

10. Könönen $M$, Waltimo $A$, Nyström $M$. Does clicking in adolescence lead to painful temporomandibular joint locking? Lancet 1996;347:1080-1081.

11. Ohno H, Morinushi T, Ohno K, Oku T, Ogura T. A longitudinal study on individual fluctuation of signs in accordance with TMJ dysfunction syndrome in adolescents. Shoni Shikagaku Zasshi 1989;27:64-73.

12. Magnusson T, Egermark I, Carlsson GE. A Longitudinal Epidemiologic Study of Signs and Symptoms of Temporomandibular Disorders from 15 to 35 Years of Age. J Orofac Pain 2000;14:310-319.

13. Wänman A. A Longitudinal course of symptoms of craniomandibular disorders in men and women. Acta Odontol Scand 1996;54:337-342.

14. Quartana PJ, Wickwire EM, Klick B, Grace E, Smith MT. Naturalistic changes in insomnia symptoms and pain in temporomandibular joint disorder: A cross-lagged panel analysis. Pain 2010;149:325331.

15. Dao TT, Knight K, Ton-That V. Modulation of myofascial pain by the reproductive hormones: A preliminary report. J Prosthet Dent 1998;79:663-670.

16. Magnusson T, Egermark I, Carlsson GE. A prospective investigation over two decades on signs and symptoms of temporomandibular disorders and associated variables. A final summery. Acta Odontol Scand 2005;63:99-109.

17. Johansson A, Unell L, Carlsson GE, Söderfeldt B, Halling A. Differences in four reported symptoms related to temporomandibular disorders in a cohort of 50-year-old subjects followed up after 10 years. Acta Odontol Scand 2008;66:50-57.

18. Epker J, Gatchel RJ, Ellis E. A model for predicting chronic TMD: practical application in clinical settings. J Am Dent Assoc 1999;130:1470-1475.

19. Rammelsberg P, LeResche L, Dworkin S, Mancl L. Longitudinal Outcome of Temporomandibular Disorders: A 5-year Epidemiologic Study of Muscle Disorders Defined by Research Diagnostic Criteria for Temporomandibular Disorders. J Orofac Pain 2003;17:9-20. 
20. Nevalainen N, Lähdesmäki R, Mäki P, Ek E, Taanila A, Pesonen P, Sipilä K. Association of stress and depression with chronic facial pain: A case-control study based on the Northern Finland 1966 Birth Cohort. Cranio 2017;35:187-191

21. Aromaa A, Koskinen S, eds. Health and Functional Capacity in Finland. Baseline results of the Health 2000 Health Examination Survey. Publications of the National Public Health Institute B12/2004. Helsinki: Hakapaino; 2004. Available at: http://www.terveys2000.fi/julkaisut/baseline.pdfhttp://www.terveys2000.fi/julkaisut/baseline.pdf.

22. Lundqvist A, Maki-Opas T, eds. Health 2011 Survey. Methods. Tampere: Juvenes Print - Suomen Yliopistopaino Oy; 2016. Available at: https://www.julkari.fi/bitstream/handle/10024/130780/URN ISBN 978-952-302-6698.pdf

23. Suominen-Taipale L, Nordblad A, Vehkalahti M, Aromaa A, eds. Oral Health in the Finnish adult population. Health 2000 Survey. Publications of the National Public Health Institute B25/2008. Helsinki: Hakapaino; 2008. 96 p.

24. Suominen AL, Varsio S, Helminen S, Nordbald A, Lahti S, Knuuttila M. Dental and periodontal health in Finnish adults in 2000 and 2011. Acta Odontol Scand 2018;16:1-9.

25. Gotfredsen K, Walls AW. What dentition assures oral function? Clin Oral Implants Res 2007;18:34-45.

26. Tervonen $\mathrm{T}$, Knuuttila M. Prevalence of signs and symptoms of mandibular dysfunction among adults aged 25, 35, 50 and 65 years in Ostrobothnia, Finland. J Oral Rehabil 1988;15:455-463.

27. Plesh O, Adams SH, Gansky SA. Racial/Ethnic and gender prevalences in reported common pains in a national sample. J Orofac Pain 2011;25:25-31.

28. Robinson ME, Riley JL, Myers CD, Papas RK, Wise EA, Waxenberg LB, Fillingim RB. Gender role expectations of pain: relationship to sex differences in pain. J Pain 2001;2:251-257.

29. Ayesh EE, Jensen TS, Svensson P. Hypersensitivity to mechanical and intra-articular electrical stimuli in persons with painful temporomandibular joints. J Dent Res 2007;86:1187-1192.

30. Sarlani E, Grace EG, Reynolds MA, Greenspan JD. Evidence for Up-regulated Central Nociceptive Processing in Patients with Masticatory Myofascial Pain. J Orofac Pain 2004;18:41-55.

31. Sarlani E, Greenspan JD. Why Look in the Brain for Answers to Temporomandibular Disorder Pain? Cells Tissues Organs 2005;180:69-75.

32. Dao TT \& LeResche L. Gender difference in pain. J Orfac Pain 2000;14:169-184.

33. Locker D, Slade G. Prevalence of symptoms associated with temporomandibular disorders in a Canadian population. Community Dent Oral Epidemiol 1988;16:310-313.

34. Aggarwal VR, Macfarlane GJ, Farragher TM, McBeth J. Risk factors for onset of chronic oro-facial pain - Results of the North Cheshire oro-facial pain prospective population study. Pain 2010;149:354-359.

35. Salonen L, Hellden L, Carlsson G.E, Prevalence of Signs and Symptoms of Dysfunction in the Masticatory System. An Epidemiologic Study in an Adult Swedish Population. J Craniomandib Disord 1990;4:241-250.

36. Swanljung O, Rantanen T. Functional disorders of the masticatory system in Southwest Finland, Community Dent Oral Epidemiol 1979;7: 177-182.

37. Slade GD, Bair E, Greenspan JD, Dubner R, Fillingim RB, Diatchenko L, Maixner W, Knott C, Ohrbach R. Signs and Symptoms of First-Onset TMD and Sociodemographic Predictors of Its Development: The OPPERA Prospective Cohort Study. J Pain 2013;14:20-32. 
38. Bordin TB, Conci RA, Pezzini MM, Pezzini RP, Mendonça MJ. Prevalence of signs and symptoms of temporomandibular disorders (TMD) in patients wearing bimaxillary complete dentures, removable partial dentures and in students with natural dentition. Acta Odontol Latinoam 2013;26:173-180.

39. Al-Jabrah OA, Al-Shumailan YR. Prevalence of temporomandibular disorder signs in patients with complete versus partial dentures. Clin Oral Investig 2006;10:167-173.

40. Witter DJ, De Haan AF, Käyser AF, Van Rossum GM.A 6-year follow-up study of oral function in shortened dental arches. Part II: Craniomandibular dysfunction and oral comfort. J Oral Rehabil 1994;21:353-366.

41. De Boever JA, Carlsson GE, Klineberg IJ. Need for occlusal therapy and prosthodontic treatment in the management of temporomandibular disorders. Part II: Tooth loss and prosthodontic treatment. J Oral Rehabil 2000;27:647-659.

42. Dervis E. Changes in temporomandibular disorders after treatment with new complete dentures. J Oral Rehabil 2004;31:320-326.

43. Dijkstra-Kersten SMA, Biesheuvel-Leliefeld KEM, van der Wouden JC, Penninx BWJH, van Marwijk HWJ. Associations of financial strain and income with depressive and anxiety disorders. J Epidemiol Community Health 2015;69:660-665.

44. Tuuliainen L, Sipilä K, Mäki P, Könönen M, Suominen AL. Association Between Clinical Signs of Temporomandibular Disorders and Psychological Distress Among an Adult Finnish Population. J Oral Facial Pain Headache 2015;29:370-377.

45. Jöud A, Petersson IF, Jordan KP, Löfvendahl S, Grahn B, Englund M. Socioeconomic status and the risk for being diagnosed with spondyloarthritis and chronic pain: a nested case-control study.

Rheumatol Int 2014;34:1291-1298. 
Table 1.

Prevalence pain on palpation of temporomandibular joints (TMJs) and masticatory muscles (MM pain) among Finnish adults who participated in the clinical oral examination and TMD signs assessment both in the Health 2000 and Health 2011 Surveys $(n=1,210)$ by gender, age group, number of teeth, denture status, and educational level.

Health 2000

Health 2011

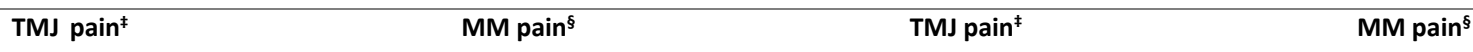

\begin{tabular}{|c|c|c|c|c|c|c|c|c|c|c|c|c|c|c|}
\hline \multirow[t]{2}{*}{ All } & Total & $n^{\pi}$ & $\%$ & $p^{*}$ & $n^{\pi}$ & $\%$ & $p^{*}$ & Total & $n^{\pi}$ & $\%$ & $p^{*}$ & $n^{\pi}$ & $\%$ & $p^{*}$ \\
\hline & 1,210 & 25 & 2.1 & & 118 & 9.5 & & 1,210 & 42 & 3.5 & & 55 & 4.6 & \\
\hline Gender & & & & 0.012 & & & $<0.001$ & & & & 0.032 & & & 0.002 \\
\hline Male & 535 & 3 & 0.6 & & 26 & 4.7 & & 535 & 12 & 2.2 & & 13 & 2.4 & \\
\hline Female & 675 & 22 & 3.3 & & 92 & 13.6 & & 675 & 30 & 4.4 & & 42 & 6.5 & \\
\hline Age & & & & 0.833 & & & 0.006 & & & & 0.340 & & & 0.181 \\
\hline-40 & 376 & 9 & 2.3 & & 33 & 8.4 & & - & - & - & & - & - & \\
\hline $41-50$ & 348 & 8 & 2.3 & & 23 & 6.5 & & 350 & 16 & 4.3 & & 14 & 4.0 & \\
\hline $51-60$ & 295 & 5 & 1.8 & & 28 & 9.3 & & 335 & 11 & 3.3 & & 13 & 4.1 & \\
\hline 61-70 & 153 & 2 & 1.2 & & 30 & 19.4 & & 322 & 7 & 2.2 & & 12 & 3.6 & \\
\hline 71- & 38 & 1 & 2.9 & & 4 & 10.4 & & 203 & 8 & 3.9 & & 16 & 8.2 & \\
\hline Number of Teeth & & & & 0.334 & & & 0.014 & & & & 0.872 & & & 0.118 \\
\hline 0 & 82 & 5 & 6.8 & & 17 & 20.8 & & 98 & 3 & 2.7 & & 7 & 7.4 & \\
\hline 1-19 & 181 & 4 & 2.2 & & 23 & 12.3 & & 203 & 7 & 3.3 & & 13 & 6.4 & \\
\hline $20+$ & 947 & 16 & 1.6 & & 78 & 8.0 & & 909 & 32 & 3.6 & & 35 & 3.9 & \\
\hline Denture status & & & & 0.456 & & & 0.022 & & & & 0.860 & & & 0.136 \\
\hline Dentate, no denture & 943 & 17 & 1.7 & & 80 & 8.2 & & 929 & 32 & 3.5 & & 36 & 4.0 & \\
\hline Dentate with denture & 184 & 3 & 1.6 & & 21 & 11.1 & & 183 & 7 & 3.7 & & 12 & 6.4 & \\
\hline Edentulous, complete denture & 83 & 5 & 6.8 & & 17 & 20.5 & & 98 & 3 & 2.7 & & 7 & 7.4 & \\
\hline Education & & & & 0.244 & & & $<0.001$ & & & & 0.844 & & & 0.001 \\
\hline Basic & 294 & 8 & 2.8 & & 55 & 18.3 & & 281 & 10 & 3.3 & & 26 & 9.1 & \\
\hline Intermediate & 394 & 10 & 2.5 & & 29 & 7.1 & & 362 & 11 & 3.1 & & 14 & 3.8 & \\
\hline Higher & 517 & 7 & 1.3 & & 24 & 6.4 & & 557 & 21 & 3.8 & & 15 & 2.7 & \\
\hline
\end{tabular}

₹ Pain in temporomandibular joint on palpation, left or right.

$\S$ Pain in either temporalis muscle or masseter, left or right.

ๆ number of affected participants

* chi2 test value 


\begin{tabular}{|c|c|c|}
\hline \multicolumn{3}{|c|}{$\begin{array}{l}\text { Table 2, } \\
\text { The association of baseline variables (in 2000) with masticatory muscle (MM) pain and temporomandibular joint (TMJ) } \\
\text { pain on palpation after the 11-year follow-up (in 2011), presented with Odds ratio (OR) and 95\% Confidence interval (CI) } \\
(\mathrm{n}=1,205) \text {. }\end{array}$} \\
\hline & $\mathrm{MM}^{\dagger}$ pain in 2011 & $\mathrm{TMJ}^{\ddagger}$ pain in 2011 \\
\hline & \multicolumn{2}{|c|}{ OR $(95 \% \mathrm{Cl})$} \\
\hline \multicolumn{3}{|l|}{ Gender } \\
\hline Male & 1.0 & 1.0 \\
\hline Female & $2.1(1.0-4.3) *$ & $2.0(1.0-3.8)$ \\
\hline Age (continuous) & $0.99(0.97-1.03)$ & $0.98(0.95-1.02)$ \\
\hline \multicolumn{3}{|l|}{ Denture status } \\
\hline Dentate, no denture & 1.0 & 1.0 \\
\hline Dentate with denture & $1.2(0.6-2.2)$ & $1.3(0.4-4.3)$ \\
\hline Edentulous, complete denture & $0.7(0.2-2.2)$ & $1.2(0.3-4.2)$ \\
\hline \multicolumn{3}{|l|}{$\mathrm{MM}^{\dagger}$ pain in 2000} \\
\hline No & 1.0 & - \\
\hline Yes & $8.2(4.7-14.4) * *$ & \\
\hline \multicolumn{3}{|l|}{$\mathrm{TMJ}^{\ddagger}$ pain in 2000} \\
\hline No & - & 1.0 \\
\hline Yes & & $1.8(0.4-7.4)$ \\
\hline \multicolumn{3}{|l|}{ Education } \\
\hline Basic & $3.7(1.9-7.3) * * *$ & $1.0(0.5-2.3)$ \\
\hline Intermediate & $2.4(1.1-5.0) * * * *$ & $0.9(0.4-1.9)$ \\
\hline Higher & 1.0 & 1.0 \\
\hline \multicolumn{3}{|c|}{$\begin{array}{l}\text { I pain in either temporalis muscle or masseter, left or right. } \\
\text { \# pain in temporomandibular joint on palpation, left or right. } \\
\text { * statistical significance }(p=0.043) \\
* * \text { statistical significance }(p<0.001) \\
* * \text { statistical significance }(p=0.001) \\
* * * \text { statistical significance }(p=0.030)\end{array}$} \\
\hline
\end{tabular}

